\title{
EFEITO ALELOPÁTICO DE CAPIM-ASSAPÊ (CIPERACEAE) NO CRESCIMENTO INICIAL DE PLÂNTULAS DE MILHO
}

\author{
Wanderson Gonçalves dos Santos ${ }^{1}$, Mariana Casari Parreira² ${ }^{2}$ Jefferson dos Santos Martins ${ }^{3}$, \\ Isabela de Oliveira Carvalho ${ }^{4}$, Evaldo Morais da Silva ${ }^{5}$
}

\begin{abstract}
RESUMO - O capim-assapê (Rhynchosphora cephalotes) é uma planta daninha perene de difícil controle, que produz substâncias químicas (compostos alelopáticos) que ao serem liberadas no meio ambiente, podem afetar o desenvolvimento de outros organismos. Este trabalho teve como objetivo verificar o potencial alelopático do capim-assapê sobre o crescimento inicial de plântulas de milho. Foram testados sete tratamentos contendo extratos aquosos da planta adulta de $R$. cephalotes, em esquema fatorial $(3 \times 3+1)$, sendo o primeiro fator, três procedências do extrato, oriundos de partes da planta (folhas, caules e raízes) e o segundo fator, três concentrações $(100,50$ e 25\%) de cada, mais uma testemunha apenas com água destilada. O experimento foi avaliado durante sete dias em câmara de germinação (CDG), sendo avaliados os seguintes parâmetros nas plântulas de milho: porcentagem de germinação, índice de velocidade de germinação, comprimento do sistema radicular, comprimento da parte aérea, peso da parte aérea, comprimento da raiz e peso da raiz. Houve efeito dos tratamentos sobre o comprimento de parte área e das raízes das plântulas de milho. Os extratos de caule e raiz de capim-assapê, na concentração de $25 \%$, proporcionaram maiores porcentagem na germinação, índice de velocidade de germinação e comprimento de raízes. O aumento da concentração para $50 \%$ proporcionou os menores valores nestes parâmetros.
\end{abstract}

Palavras chave: metabolito secundário, plantas daninhas, Rhynchosphora cephalotes L.

\section{ALLELOPATHIC EFFECT OF ASSAPPE GRASS (CIPERACEAE) ON CORN SEEDLINGS}

\begin{abstract}
Assappe grass (Rhynchosphora cephalotes L.) is a hard-to-control perennial weed that can produce chemicals (allelopathic compounds) that, when released into the environment, impair or benefit the development of other organisms. to verify the allelopathic potential of Rhynchospora cephalotes on early seedling growth of maize. Seven treatments containing aqueous extracts of the $R$. cephalotes adult plant were tested in a factorial scheme $(3 \times 3+1)$, and three types of extracts from the vegetative parts of the plant (leaves, stems and roots) in three concentrations (100, 50 and 25\%) each, plus one witness with distilled water only. The experiment was evaluated for 7 days in a germination chamber (CDG), observing the following parameters: germination percentage, germination speed index, root system length, aerial part length, aerial part weight, root length and root weight. root. Potential of this species was verified, which positively influenced the length of part area and root length of corn seedlings. Among the extracts, stem and root treatments at concentrations of $100 \%$ and $25 \%$ provided the highest percentage in germination, germination speed index and root length, and the 50\% leaf extract provided the lowest values in these parameters.
\end{abstract}

Keywords: Rhynchosphora cephalotes L., secondary metabolite, weeds.

\footnotetext{
'Faculdade de Agronomia (FAGRO). Campus Universitário do Tocantins (CUNTINS). Universidade Federal do Pará. UFPA. Email: wendell88goncalves@gmail.com ${ }^{1}$; mcparreira@ufpa.br ${ }^{2}$; santos-jeff@hotmail.com ${ }^{3}$; isaocmg@hotmail.com ${ }^{4}$; evaldo.morais@ufpa.br ${ }^{5}$
} 


\section{INTRODUÇÃO}

Tem sido observado que algumas plantas daninhas produzem substâncias químicas provenientes do metabolismo secundário que afetam de diferentes formas o desenvolvimento de outras espécies de plantas (Melhorança Filho et al., 2011). Esses metabólitos, denominados substâncias alelopáticas, podem afetar estruturas citológicas, concentração e balanço fito-hormonais, permeabilidade de membranas, absorção de nutrientes, movimentos estomáticos, síntese de proteínas, atividades enzimáticas, relações hídricas, induzir a alterações no material genético (Coelho et al., 2014). Além disso, os efeitos também podem ser variados quando se considera em qual órgão da planta eles estão atuando.

A espécie Rhynchosphora cephalotes L., popular capim-assapê, é considerada uma planta invasora muito conhecida devido a sua capacidade de multiplicação. É uma planta de difícil manejo e causadora de prejuízos em diversas culturas anuais. Encontrada em áreas de exploração agrícola desgastadas, principalmente em solos ácidos, que se apresenta como uma das condições ideal para sobrevivência.

Por ser uma espécie extremamente agressiva, ela figura como uma das plantas daninhas mais importantes do meio amazônico principalmente no Baixo Tocantins, infestando áreas de cultivos perenes e pastagens degradadas, sendo de difícil manejo, no qual inviabiliza práticas culturais devido ao grande adensamento de plantas (Falcão-da-Silva et al., 2016).

Através do exposto, este trabalho teve como objetivo verificar o potencial efeito alelopático da espécie $R$, cephalotes sobre o crescimento inicial de plântulas de milho.

\section{MATERIAL E MÉTODOS}

O trabalho foi realizado no mês de maio de 2019, no Laboratório de Fitossanidade da Amazônia Tocantina (LAFAT), no Campus Universitário do Tocantins (CUNTINS) - Universidade Federal do Pará (UFPA). Foram testados dez tratamentos contendo extratos aquosos da planta adulta de $R$. cephalotes, em esquema fatorial ( $3 \mathrm{x}$ $3+1$ ), sendo três extratos oriundos de partes vegetativa da planta (folhas, caules e raízes) em três concentrações (100, 50 e $25 \%$ ), mais uma testemunha com água destilada. O delineamento utilizado foi o inteiramente casualizado, com quatro repetições. Os tratamentos foram os seguintes: T1 Caule 25\%; T2 - Caule 50\%; T3 - Caule 100\%; T4 - Folha
25\%; T5 - Folha 50\%; T6 - Folha 100\%; T7 - Raiz 25\%; T8

- Raiz 50\%; T9 - Raiz 100\%; e T10 - Testemunha.

As plantas de capim assapê, em pleno estádio vegetativo, utilizadas para a preparação dos extratos, foram coletadas em áreas de agricultores familiares do município de Cametá-PA. Após a coleta, as plantas foram separadas em caule, folha e raiz e acondicionadas em local seco até a realização do experimento. Os extratos aquosos (solução estoque), ambos de $20 \%$ (20\% de material vegetal e $80 \%$ de água), foram obtidos através da trituração de suas partes com água destilada em liquidificador, segundo metodologia de Bortolini \& Teixeira Fortes (2005). A partir desta solução foram feitas as diluições no qual foram distribuídas de acordo com cada tratamento. As sementes de milho utilizadas no experimento foram adquiridas no comércio local, sendo sementes de variedade crioula.

As unidades experimentais, foram formadas por recipientes de plástico com dimensão de $31,5 \mathrm{~cm}$, com papel filtro autoclavado, umedecidos com $2 \mathrm{ml}$ de cada tratamento. Após a adição das sementes de milho, as unidades experimentais foram acondicionadas em câmara de germinação - CDG, sob condições controladas de temperatura $\left(25^{\circ} \mathrm{C}\right)$ e fotoperíodo (12 horas). As avaliações laboratoriais perduraram sete dias após a instalação do experimento.

A germinação das sementes foi avaliada diariamente e após finalizado o período experimental foram obtidos a porcentagem de germinação $(\mathrm{G} \%)$; índice de velocidade de germinação (IVG) (Maguire, 1963); comprimento do sistema radicular $(\mathrm{CR})(\mathrm{cm})$; comprimento da parte aérea $(\mathrm{CPA})(\mathrm{cm})$; peso da parte aérea (PPA) $(\mathrm{g})$ e peso das raiz $(\mathrm{PR})(\mathrm{g})$.

Os dados obtidos foram submetidos à análise de variância (ANOVA), e as médias dos tratamentos, quando significativas, comparadas pelo teste de Tukey a $5 \%$ de probabilidade, utilizando-se o programa estatístico AgroEstat.

\section{RESULTADOS E DISCUSSÃO}

Ao analisar os tratamentos com extratos com $R$. cephalotes, os parâmetros de comprimento da parte área (CPA) e comprimento de raízes (CR) foram diferenciados da testemunha, exercendo influência no desenvolvimento nesses parâmetros (Tabela 1); nos demais, os extratos aquosos e suas concentrações não afetaram o crescimento inicial das plântulas de milho, obtendo valores significativos iguais ao da testemunha. 
Tabela 1 - Valores médios da porcentagem de germinação - G(\%), Indice de Velocidade de Germinação (IVG), Comprimento da Parte Aérea (CPA) (cm), Comprimento de Raízes (CR) (cm), Peso da Parte Aérea (PPA) (g) e Peso da Raízes (PR) (g) de milho, em função dos extratos de R. cephalotes nas diferentes concentrações

\begin{tabular}{|c|c|c|c|c|c|c|}
\hline & G\% & IVG & CPA & PPA & $\mathrm{CR}$ & PR \\
\hline \multicolumn{7}{|c|}{ Partes da planta } \\
\hline Caule & $83,75 \mathrm{~A}$ & $14,51 \mathrm{~A}$ & $3,64 \mathrm{~A}$ & $4,88 \mathrm{~A}$ & $7,04 \mathrm{~A}$ & $5,01 \mathrm{~A}$ \\
\hline Folha & $67,08 \mathrm{~B}$ & $11,25 \mathrm{~B}$ & $3,67 \mathrm{~A}$ & $5,01 \mathrm{~A}$ & $6,68 \mathrm{~A}$ & $4,95 \mathrm{~A}$ \\
\hline Raiz & $72,50 \mathrm{AB}$ & $12,60 \mathrm{AB}$ & $3,58 \mathrm{~A}$ & $4,89 \mathrm{~A}$ & $7,37 \mathrm{~A}$ & $4,95 \mathrm{~A}$ \\
\hline \multicolumn{7}{|c|}{ Concentrações do extrato bruto } \\
\hline $100 \%$ & $75,41 \mathrm{AB}$ & $13,28 \mathrm{AB}$ & $3,84 \mathrm{~A}$ & $4,95 \mathrm{~A}$ & $7,51 \mathrm{~A}$ & $4,86 \mathrm{~A}$ \\
\hline $50 \%$ & $67,91 \mathrm{~B}$ & $11,30 \mathrm{~B}$ & $3,30 \mathrm{~A}$ & $4,92 \mathrm{~A}$ & $6,31 \mathrm{~A}$ & $5,06 \mathrm{~A}$ \\
\hline $25 \%$ & $80,00 \mathrm{~A}$ & $13,79 \mathrm{~A}$ & $3,34 \mathrm{~A}$ & $4,91 \mathrm{~A}$ & $7,37 \mathrm{~A}$ & $4,99 \mathrm{~A}$ \\
\hline F (partes.planta) & $6,52 * *$ & $7,44^{* *}$ & $0,54 \mathrm{NS}$ & $2,52 \mathrm{NS}$ & $0,56 \mathrm{NS}$ & $0,16 \mathrm{NS}$ \\
\hline F (concentraçoes) & $3,35^{*}$ & $4,77^{*}$ & $1,25 \mathrm{NS}$ & $0,18 \mathrm{NS}$ & $2,37 \mathrm{NS}$ & $1,70 \mathrm{NS}$ \\
\hline$F^{\text {(p.planta. } x \text { conc..) }}$ & $4,39 * *$ & $4,93 * *$ & $1,91 \mathrm{NS}$ & $1,06 \mathrm{NS}$ & $4,44 * *$ & $1,55 \mathrm{NS}$ \\
\hline Média Fatorial & 74,44 & 12,79 & 3,49 & 4,93 & 7,08 & 4,97 \\
\hline Média Testemunha & 47,75 & 11,97 & 2,19 & 4,93 & 1,94 & 4,98 \\
\hline F Fatorial x Testemunha & $0,01 \mathrm{NS}$ & $0,55 \mathrm{NS}$ & $6,97 *$ & $0,01 \mathrm{NS}$ & $36,28 * *$ & $0,01 \mathrm{NS}$ \\
\hline $\mathrm{CV}(\%)$ & 15,51 & 16,37 & 27,78 & 3,22 & 24,58 & 5,35 \\
\hline
\end{tabular}

Médias seguidas de mesma letra, na coluna, não diferem entre si no teste de Tukey. *, ** significativo a 5 e $1 \%$ de probabilidade, respectivamente. NS- não-significativa, $\mathrm{CV}(\%)=$ coeficiente de variação.

Os extratos de $R$. cephalotes estimularam o comprimento da parte área e das raízes, aumentando, em média, mais de 6 centímetros as raízes das plântulas de milho quando presente o extrato de raiz a $25 \%$. Estímulo semelhante foi proporcionado com o extrato de folha a $100 \%$, com aumento em média, de mais $5 \mathrm{~cm}$ nas raízes (Figura 1). Scheren et al. (2014) ao analisarem o efeito da aplicação de extrato aquoso de bulbo e rizoma de Cyperus rotundus L, verificaram que o extrato aquoso na concentração de 7,5\% ativou o crescimento radicular e da parte aérea as plântulas de milho, em comparação com a testemunha.

O extrato da folha na concentração de $100 \%$ também proporcionou aumento na parte área, em média, 2 $\mathrm{cm}$, juntamente com extrato de caule a $50 \%$, que acarretou no crescimento, em média, de mais de $1 \mathrm{~cm}$ quando comparadas as plântulas da testemunha (Figura 1). Prates et al. (2000) citam que nem todas as substâncias liberadas pelas plantas causam problemas de deletérios, ao contrário, podem estimular.
Ao analisar os fatores independentemente foi observado efeito das partes da planta e das concentrações sobre a germinação e o índice de velocidade da germinação (e, os extratos de partes das plantas obtiveram resultados distintos, influenciando somente a germinação e o IVG (Tabela 1). A maior porcentagem de germinação foi obtida com extrato aquoso de caule (acima de 83\%) e consequentemente maior índice de velocidade de germinação $(14,51)$. Com os extratos feitos de folha de $R$. cephalotes, a porcentagem de germinação foi reduzida $19,9 \%$ e o IVG diminuiu $22,5 \%$, quando comparados com as plântulas presentes no extrato aquoso de caule, seguido pelos extratos de raiz que proporcionaram valores de $72,50 \%$ de germinação e IVG de 12,60 .

O efeito alelopático dos extratos de folhas secas e verdes de mamona (Ricinus communis) foi verificado que germinação e o índice de velocidade de germinação das sementes de milho foram reduzidas à medida que se aumentava as concentrações destes extratos (Muniz et al., 2007). 


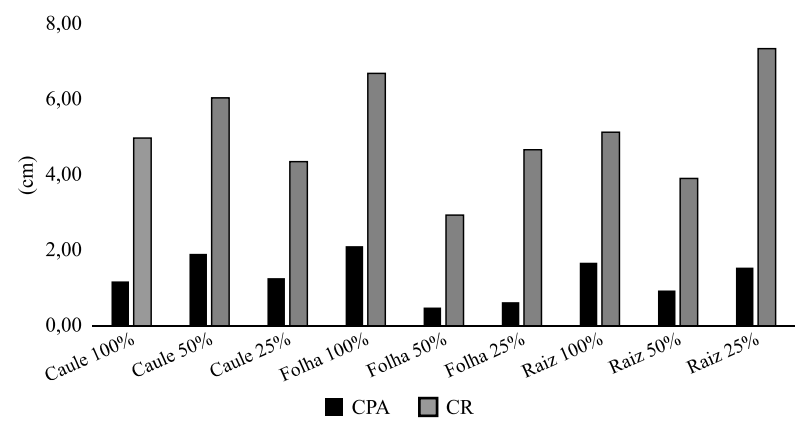

Figura 1 - Aumento $(\mathrm{cm})$ das variáveis: Comprimento da parte aérea (CPA) e comprimento de raízes (CR) das plântulas de milho em função dos extratos de $R$. cephalotes e suas concentrações de acordo com os tratamentos em comparação com as plântulas presentes na testemunha.

Ao analisar as concentrações separadamente, observou-se que a concentração de $25 \%$ foi a que proporcionou maiores G (\%) e IVG, atingindo $80 \%$ na germinação e 13,78 no índice de velocidade de germinação, juntamente com a concentração de $100 \%$ com 75,41 de G (\%) e IVG de 13,28. Nos demais parâmetros a concentração dos extratos não foi determinante (Tabela 1).

Em relação a interação dos fatores, ocorreram influência nos parâmetros de G (\%), IVG e CR (Tabela 1), mostrando que os diferentes extratos nas diferenças concentrações afetaram as plântulas de milho diferentemente entre si.

O extrato de caule proporcionou os maiores valores de germinação ( $80 \%$ ou mais), em todas as concentrações utilizadas. Nos extratos de folha, as concentrações de 100 e $25 \%$ obtiveram germinação de 70 a $80 \%$. O extrato de raiz obteve altos valores de germinação somente na concentração de $25 \%$ (Tabela 2). Entretanto, a menor germinação foi obtida com o tratamento com o extrato de folha a $50 \%$, acarretando no menor valor do experimento, não atingindo $52 \%$ de germinação das sementes de milho.

No índice de velocidade de germinação, o mesmo comportamento foi verificado no parâmetro anterior (Tabela 3), no qual os extratos de caule proporcionaram altos valores de IVG, acima de 14. Os extratos de folha nas concentrações de 100 e $25 \%$ obtiveram valores entre 11,66 a 13,91. Contudo, o maior valor neste parâmetro foi obtido nas plântulas presentes no extrato de raiz a $25 \%$, superando o índice de 15,5 . O menor valor de IVG foi obtido com a solução de folha a 50\%, não atingido 8,2 neste índice.
Tabela 2 - Porcentagem de germinação das plântulas de milho em função dos extratos de $R$. cephalotes em diferentes concentrações, de acordo com os tratamentos.

\begin{tabular}{lccc}
\hline Concentração & Caule & Folha & Raiz \\
\hline $100 \%$ & $80,00 \mathrm{~A} \mathrm{a}$ & $80,00 \mathrm{~A} \mathrm{a}$ & $66,25 \mathrm{~A} \mathrm{~b}$ \\
$50 \%$ & $88,75 \mathrm{~A} \mathrm{a}$ & $51,25 \mathrm{~B} \mathrm{~b}$ & $63,75 \mathrm{~B} \mathrm{~b}$ \\
$25 \%$ & $82,50 \mathrm{~A} \mathrm{a}$ & $70,00 \mathrm{~A} \mathrm{ab}$ & $87,51 \mathrm{~A} \mathrm{a}$ \\
\hline
\end{tabular}

Médias seguidas da mesma letra, não diferem entre si pelo teste de Tukey $(\mathrm{P} \leq 0,05)$, sendo que letras minúsculas comparam o efeito das partes de planta (vertical) e maiúsculas comparam o efeito concentrações (horizontal).

Tabela 3 - Índice de velocidade de germinação das plântulas de milho em função dos extratos de $R$. cephalotes em diferentes concentrações, de acordo com os tratamentos

\begin{tabular}{lccc}
\hline Concentração & Caule & Folha & Raiz \\
\hline $100 \%$ & $14,10 \mathrm{~A} \mathrm{a}$ & $13,91 \mathrm{~A} \mathrm{a}$ & $11,83 \mathrm{~A} \mathrm{~b}$ \\
$50 \%$ & $15,31 \mathrm{~A} \mathrm{a}$ & $8,18 \mathrm{~B} \mathrm{~b}$ & $10,41 \mathrm{~B} \mathrm{~b}$ \\
$25 \%$ & $14,14 \mathrm{AB} \mathrm{a}$ & $11,66 \mathrm{~B} \mathrm{ab}$ & $15,56 \mathrm{~A} \mathrm{a}$ \\
\hline
\end{tabular}

Médias seguidas da mesma letra, não diferem entre si pelo teste de Tukey $(\mathrm{P} \leq 0,05)$, sendo que letras minúsculas comparam o efeito das partes de planta (vertical) e maiúsculas comparam o efeito concentrações (horizontal).

Os extratos de caule, em todos as concentrações utilizadas, proporcionaram comprimentos semelhantes, variando de 6,27 a 7,95 cm nas raízes de milho (Tabela 4). Nos extratos de folha as maiores raízes foram obtidas nas concentrações de $100 \%$ e $25 \%$ oscilando 6,58 a 8,60 $\mathrm{cm}$, as plântulas presentes nos extratos de raízes a $100 \%$ e $25 \%$ também obtiveram altos valores com $7,05 \mathrm{~cm}$ e 9,25 $\mathrm{cm}$ respectivamente. Novamente o extrato de folha a $50 \%$ proporcionou o menor comprimento de raiz, não atingindo $5 \mathrm{~cm}$ de comprimento.

\section{CONCLUSÃO}

Os extratos de caule em todas as concentrações e de raiz na concentração de $25 \%$ proporcionaram altos números de germinação, índice de velocidade de germinação e comprimento de raízes, sendo que o extrato de folha a $50 \%$ proporcionou os menores valores nestes parâmetros. 
Tabela 4 - Comprimento de raízes $(\mathrm{cm})$ das plântulas de milho em função dos extratos de $R$. cephalotes em diferentes concentrações, de acordo com os tratamentos

\begin{tabular}{lccc}
\hline Concentração & Caule & Folha & Raiz \\
\hline $100 \%$ & $6,89 \mathrm{~A} \mathrm{a}$ & $8,60 \mathrm{~A} \mathrm{a}$ & $7,05 \mathrm{~A} \mathrm{ab}$ \\
$50 \%$ & $7,95 \mathrm{AB} \mathrm{a}$ & $4,86 \mathrm{~B} \mathrm{~b}$ & $5,83 \mathrm{AB} \mathrm{b}$ \\
$25 \%$ & $6,27 \mathrm{~B} \mathrm{a}$ & $6,58 \mathrm{AB} \mathrm{ab}$ & $9,25 \mathrm{~A} \mathrm{a}$ \\
\hline
\end{tabular}

Médias seguidas da mesma letra, não diferem entre si pelo teste de Tukey $(\mathrm{P} \leq 0,05)$, sendo que letras minúsculas comparam o efeito das partes de planta (vertical) e maiúsculas comparam o efeito concentrações (horizontal).

\section{LITERATURA CITADA}

BORTOLINI, M.F.; TEIXEIRA FORTES, A.M. Efeitos alelopáticos sobre a germinação de sementes de soja (Glycine max L.Merrill). Semina: Ciências Agrárias, v. 26, n. 1, p. 5-10, 2005.

COELHO, F.M.; OLIVEIRA, S.G.; BALIZA, D.P. et al. Efeito de extratos de plantas espontâneas na germinação e no crescimento inicial do feijão comum. Revista Brasileira de Agroecologia, v. 9, n. 2, p.185-192, 2014.
FALCÃO-DA-SILVA, M.; SOUZA FILHO, A.P.S.; GURGEL, E.S.C. et al. Plantas Daninhas na Amazônia. Belém: Museu Paraense Emílio Goeldi, 2016. v.1. 188p.: il.

MAGUIRE, J.D. Speed of germination aid in selection and evaluation for seedling emergence and vigor. Crop Science, v. 2, n. 2, p. 176-177, 1963.

MELHORANÇA FILHO, A.L.; OLIVEIRA, W.S.; OLIVEIRA JUNIOR, P.P.; ARAÚJO, M.L. Potencial alelopático de diferentes espécies de plantas daninhas sobre o desenvolvimento de plântulas de feijão. Ensaios $e$ Ciência, v. 15, n. 5, p. 31-40, 2011.

MUNIZ, F.R.; CARDOSO, M.G.; PINHO, E.V.R.V.; VILELA, M. Qualidade fisiológica de sementes de milho, feijão, soja e alface na presença de extrato de tiririca. Revista Brasileira de Sementes, v. 29, n. 2, p. 195-204, 2007.

PRATES, H.T.; PAES, J.M.V.; PIRES, N.M.; PEREIRA FIHO, I.A.; MAGALHÃES, P.C. Efeito do extrato aquoso de leucena na germinação e no desenvolvimento do milho. Pesquisa Agropecuária Brasileira, v. 35, n. 5, p. 909-914, 2000.

SCHEREN, M.A.; RIBEIRO, V.M.; NOBREGA, L.H.P. Efeito alelopático de tiririca (Cyperus rotundus L.) sobre o desenvolvimento de milho (Zea mays L.). Journal of Agronomic Sciences, Umuarama, v. 3, n. 1, p. 308-316, 2014.

Recebido para publicação em 04/09/2019 e aprovado em 23/12/2019. 